\title{
Applicability of Reporter Genes to Carnation Transformation
}

\author{
Alexander Vainstein ${ }^{1,3}$, Morly Fisher, and Meira Ziv ${ }^{2}$ \\ The Otto Warburg Center for Biotechnology in Agriculture, Faculty of \\ Agriculture, The Hebrew University of Jerusalem, Rehovot 76-100, Israel
}

Additional index words. Dianthus caryophyllus, 4-methylumbelliferone, 4methylumbelliferyl glucuronide, phenolic compounds, polyvinylpolypyrrolidone, chloramphenicol acetyltransferase, $\beta$ - glucuronidase

\begin{abstract}
The applicability of $\beta$ - glucuronidase and chloramphenicol acetyltransferase reporter genes to a carnation (Dianthus caryophyllus $\mathbf{L}$.) transformation procedure, was analyzed. Transgenic tobacco (Nicotiana tabacum L.) plants expressing the respective reporter genes were prepared and used as the enzyme source. Carnation leaf extract strongly inhibited enzymatic activity of $\beta$ - glucuronidase, but not that of chloramphenicol acetyltransferase. One or more carnation phenolic compounds, acting in a noncompetitive manner, is suggested as the cause of the observed inhibition of fluorometrically assayed $\beta$ glucuronidase activity. This inhibition was eliminated by treating the carnation leaf extract with polyvinylpolypyrrolidone.
\end{abstract}

Carnation is one of the major contributors to the cut-flower market worldwide and therefore has been an important target for the classical breeding of new varieties with novel characteristics. Recently, a particularly attractive methodology for introducing new plant characteristics has been developed: the use of genetic transformation systems, which already has had a large impact on breeding new plant types. Transgenic plants with herbicide resistance, resistance to viral infection, tolerance to insects, and novel flower colors have been produced (Carlton, 1990; Clark et al., 1990; Dekeyser et al., 1990; Meyer et al., 1987; Mol et al., 1990). However, efficient transformation systems have been developed only for a handful of species. Systems for transforming cut flowers of major importance to the ornamental industry, such as carnation and rose, are being developed currently (Lu et al., 1991, 1992).

Transformation systems are established based on the availability of storable and selectable marker genes. Genes coding for $\beta-$ glucuronidase (GUS) and chloramphenicol acetyltransferase (CAT) are among the most useful reporter genes (Herrera-Estrella et al., 1988; Jefferson, 1987; Jefferson et al., 1987). The superiority of GUS over other storable marker genes lies in the simplicity and accuracy with which its level of expression can be

Received for publication 4 Dec. 1992. Accepted for publication 14 June 1993. We are grateful to $\mathrm{R}$ Fluhr, M. Marikovsky, and M. Volokita for generously providing the binary vectors. This study was supported by a grant from the Robert Szold Institute for Applied Science of the P.E.F. Israel Endowment Fund and the Carnation Growers Fund (Association of Israeli Flower Growers) to A.V. The cost of publishing this paper was defrayed in part by the payment of page charges. Under postal regulations, this paper therefore must be hereby marked advertisement solely to indicate this fact.

'Dept. of Horticulture.

${ }^{2}$ Dept. of Agricultural Botany.

${ }^{3}$ To whom reprint requests should be addressed. quantified, or histochemically determined (Jefferson, 1987; Jefferson et al., 1987). Since plant metabolic and structural activities can affect foreign gene expression (Plegt and Bino, 1989), or compounds inhibiting foreign enzyme activity can be present (Fromm et al., 1987), we analyzed the applicability of GUS and CAT reporter genes to carnation transformation. A study of the factors in carnation leaf extract responsible for the inhibition of GUS but not CAT activity is presented. An optimized GUS activity assay that eliminates the effect of these factors is presented also.

Plant material and transformation. Tobacco var. SR-I and 'White Sire', 'Rubina', and 'Sandrosa' carnation plants were grown in a glasshouse at 18 to $25 \mathrm{C}$ under natural photoperiod. Tobacco plants transformed with bacterial GUS or CAT genes were obtained using disarmed Agrobacterium tumefaciens binary vectors LBA4404(pBI121) (gift of M. Volokita, the Weizmann Institute of Science, Israel) or EHA101(p35S-GA492) (gift of M.

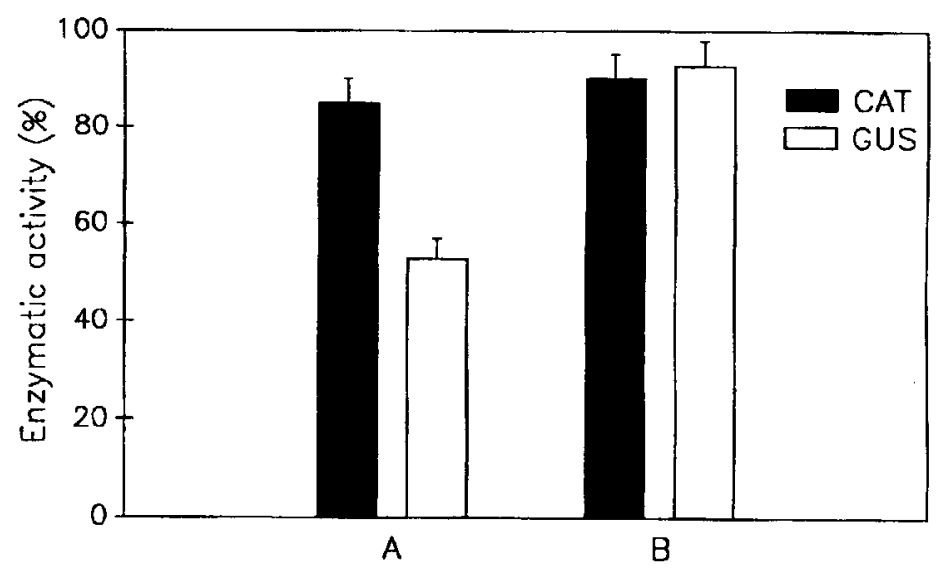

Fig. 1. The effects of carnation leaf extract on GUS and CAT reporter gene activities. Relative GUS and CAT enzyme activities in leaf extracts of respectively transformed tobacco plants were assayed in the presence of (A) carnation or (B) mock-transfected tobacco leaf extracts. Activities are given as the percentage over that found in transgenic tobacco leaf extract alone. All enzymatic reactions were carried out for $50 \mathrm{~min}$ at $37 \mathrm{C}$. Bars represent the average of three independent experiments, and SD for each bar is indicated. 


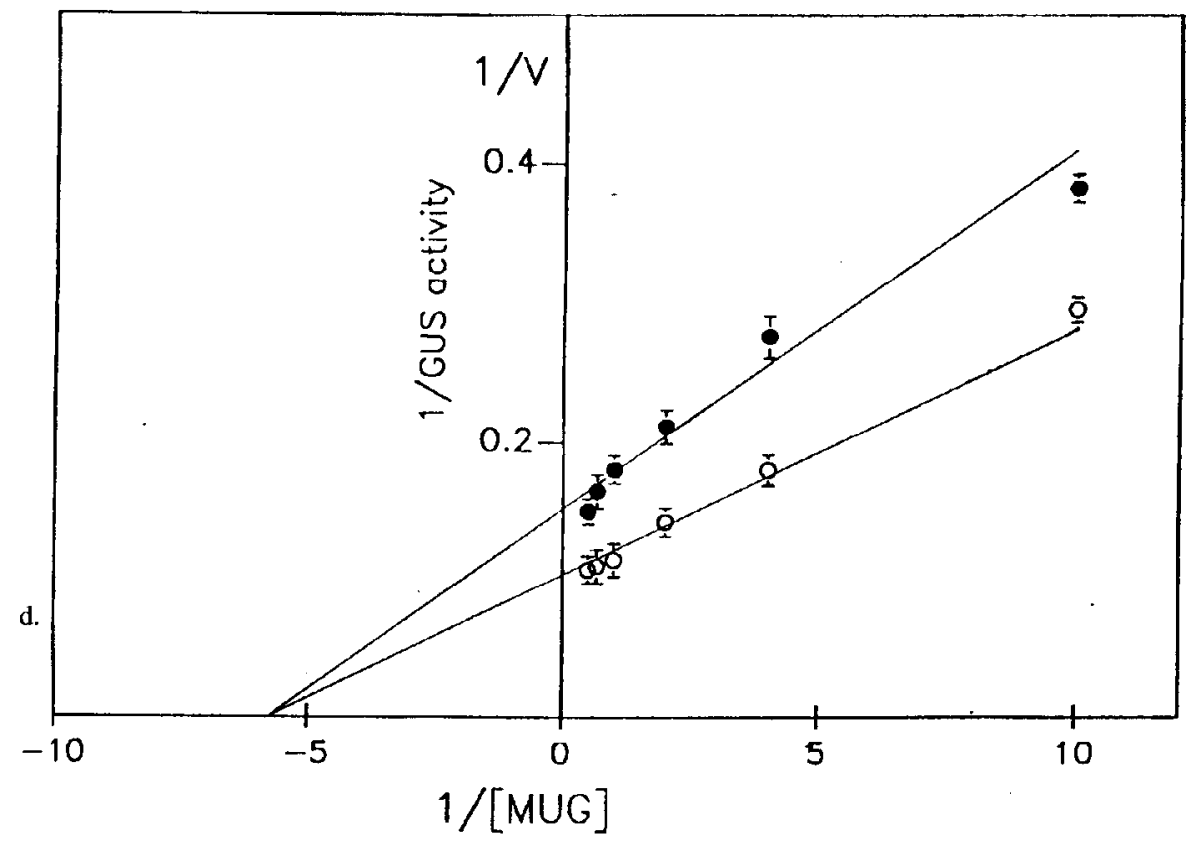

Fig. 2. Lineweaver-Burk plot showing noncompetitive inhibition of GUS activity by carnation leaf extract. 35S-GUS tobacco leaf extract was assayed in the $(\Theta)$ presence or $(O)$ absence of camation leaf extract. Each point represents the average of three replications, and SD is indicated by bars.

nation leaf extract to the leaf extract from a tobacco plant transformed with 35S-GUS resulted in an apparent inhibition of GUS activity (Fig. 1A). Adding leaf extracts from 'Rubina' and 'Sandrosa' carnation produced identical inhibition patterns (data not shown). Only a slight reduction in GUS activity was detected when leaf extract from control mocktransfected tobacco was added (Fig. 1B). The CAT activity of 35S-CAT tobacco leaf extract was affected only slightly when assayed in the presence of either carnation or mock-transfected tobacco leaf extracts (Fig. 1). These results indicate the specific GUS activity inhibition by carnation leaf extract, rather than a general inhibition of foreign enzyme activity. No intrinsic GUS or CAT activity was detected in the leaf extracts of either carnation or mock-transfected tobacco plants (data not shown).

Carnation compound(s) responsible for GUS activity inhibition. To determine the cause of GUS activity inhibition by carnation leaf extract, we measured the $\mathrm{pH}$ of the reaction mixture in the presence and absence of the extract. In both cases, the $\mathrm{pH}$ was 6.6 , which is within the optimal enzyme activity assay range (Jefferson et al., 1987). The substrate also was not found to be a limiting factor increased MUG concentrations in the reaction mixture had no effect on reaction rate (data not shown). Therefore, the reaction conditions apparently were not responsible for the observed carnation-induced GUS activity inhibition. GUS activity inhibition was found to be noncompetitive (Fig. 2), as determined from a Lineweaver-Burk plot, described in Hammes (1982). The Km was calculated to be $0.5 \mathrm{~mm}$, which is similar to that found for this enzyme from mammalian sources (Frederick et al., 1978). The carnation leaf extract could have been affecting the reaction product, 4methylumbelliferone (MU), thereby causing
GUS reaction mixture did not influence its inhibitory effect (Fig. 3), suggesting that the compounds in the carnation extract responsible for inhibiting GUS activity were not proteinaceous.

Treating the carnation leaf extract with PVPP before adding leaf extract to the reaction mixture eliminated its inhibitory effect (Fig. 3). Also, treating 35S-GUS tobacco leaf extract with PVPP had almost no effect on GUS activity. These results suggest that at least one phenolic compound present in the carnation leaf extract is involved in GUS activity inhibition, since PVPP is known to absorb phenols specifically (Loomis, 1974). Further, the activity of an enzyme native to carnation has been shown to be inhibited by a carnation phenolic compound (Shih et al., 1989). Also, Jefferson (1987) suggested that PVPP can be used to extract plant tissues containing high levels of polyphenols.

Results of the present study suggest that at least one compound in carnation leaf extract, most probably phenolic in nature, strongly inhibits GUS but not CAT activity. Treating the carnation leaf extract with PVPP eliminates this inhibition. We, therefore, recommend the PVPP treatment step as a routine procedure in fluorometric GUS activity measurements, where a carnation transformation procedure is to be established using the GUS reporter gene. Since CAT activity was found to be almost unaffected by the carnation leaf extract, the use of CAT rather than GUS reporter genes may prove advantageous in establishing an efficient carnation transformation system. However, the pattern of GUS or CAT activity in vivo in transgenic carnation may differ from that of the in vitro pattern presented here.

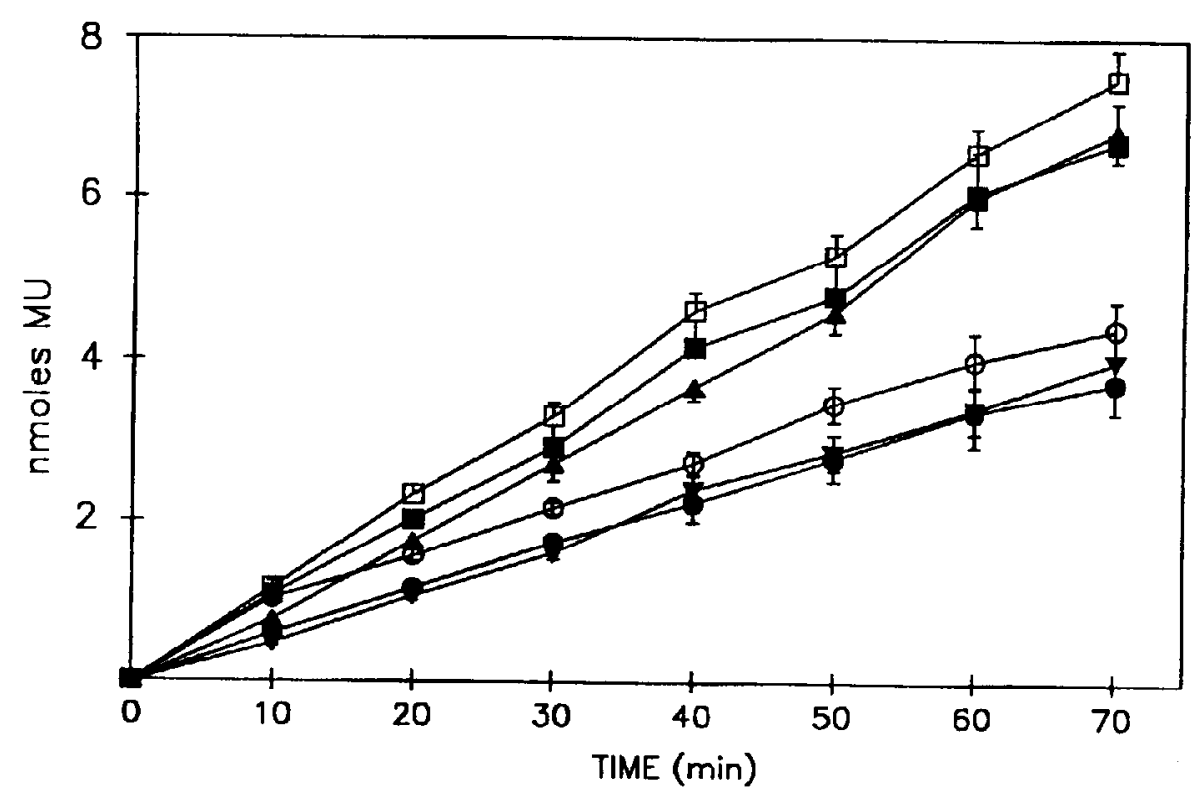

Fig. 3. Characterization of the carnation leaf extract compound(s) inhibiting GUS activity. GUS activity kinetics in 35S-GUS tobacco leaf extract (D) treated or ( $\square$ ) nontreated with PVPP. The nontreated tobacco leaf extract also was assayed in the presence of $(\boldsymbol{\theta})$ carnation leaf extract, $(\Delta)$ PVPP-treated carnation leaf extract, or $(\boldsymbol{\nabla})$ boiled carnation leaf extract; $(O)$ carnation leaf extract added to the nontreated tobacco extract $10 \mathrm{~min}$ after the beginning of the reaction. Each point represents the average of three independent experiments. SD smaller than the symbol size is not indicated. 


\section{Biotechnology}

\section{Literature Cited}

An, G. 1986. Development of plant promoter expression vectors and their use for analysis of differential activity of nopaline synthase promoter in transformed tobacco cells. Plant Physiol. 81:86-91.

Carlton, B.C. 1990. Biology of Bacillus thuringiensis: A bacterial insecticide, p. 263-271. In: A.B. Bennett and S.D. O'Neill (eds.). Plant biology. vol. 11. Wiley-Liss, New York.

Clark, W.J., J. Register, and R.N. Beachy. 1990. Engineering virus resistance in transgenic plants p. 273-283. In: A.B. Bennett and S.D. O'Neill (eds.). Plant biology. vol. 11. Wiley-Liss, New York.

Dekeyser, R., D. Inze, and M. Van Montago. 1990. Transgenic plants, p. 237-250. In J.P. Gustafson (ed.). Gene manipulation in plant improvement. vol. II. Plenum Press, New York.

Frederick, E.B., C.E. Bell, and W.S. Sly. 1978. purification and properties of $\beta$ - glucuronidase from human placenta. Amer. Chem. Soc. 17:385391.

Fromm, M., J. Callis, L.P. Taylor, and V. Walbot. 1987. Electroporation of DNA and RNA into plant protoplasm, p. 351-366. In: J.N. Abelon and M.I. Simon (eds.). Methods in enzymology. vol. 153. Academic, New York.

German, C. M., L.F. Moffat, and B.H. Howard.
1982. Recombinant genomes which express chloramphenicol acetyltransferase in mammalian cells. Mol. Cell Biol. 2:1044-1051.

Hammes, G.G. 1982. Enzyme catalysis and regulation. Academic, New York.

Herrera-Estrella, L., T.H. Teeri, and J. Simpson. 1988. Use of reporter genes to study gene expression in plant cells, p. 1-22. In: S.B. Gelvin, R.A. Schilperoort, and D.P.S. Verma (eds.). Plant molecular biology manual. B1. Kluwer Academic Publishers, Belgium.

Hood, E.E., G.L. Helmer, and R.T. Fraley. 1986. The hypervirulence of Agrobacterium tumefaciens A281 is encoded in a region of pTiBo542 outside of T-DNA. J. Bacteriol. 168:1291-1301.

Horsh, R.D., J.E. Fry, N.L. Hoffman, D. Eichnotz, J.S. Rogers, and R. Fraley. 1985. A simple and general method for transferring genes into plants. Science 227:1229-1231.

Jefferson, R.A. 1987. Assaying chimeric genes in plants: The GUS gene fusion system. Plant Mol. Biol. Rpt. vol. 5.4:387-405.

Jefferson, R.A., T.A. Kavanagh, and M.W. Bevan. 1987. GUS fusion: $\beta$ - glucuronidase as a sensitive and versatile gene fusion marker in higher plants. EMBO J. 6:3901-3907.

Loomis, W.D. 1974. Overcoming problems of phenolics and quinones in the isolation of plant enzymes and organelles, p. 328-544. In: S. Fleicher and L. Packer (eds.). Methods in enzy- mology. vol. 31. Academic, New York.

Lu, C., G. Nugent, T. Wardley-Richardson, S.F, Chandler, R. Young, and M.J. Dalling. 1991. Agrobacterium- mediated transformation of carnation (Dianthus caryophyllus L.). Bio/Technology 9:864-868.

Lu, C., G. Nugent, S. Tsuda, and R. Young. 1992. The effect of thidiazuron and other cytokinins on plant regeneration and transformation in carnation and rose. In Vitro Cell. Dev. Biol. 28:57A. (Abstr.)

Meyer, P., I. Heidmann, G. Forkmann, and H. Saedler. 1987. A new petunia flower colour generated by transformation of a mutant with a maize gene. Nature (London) 330:667-668.

Mol, J.N.M., A.R. van der Krol, and A.R. Stuitje. 1990. Manipulating of floral pigmentation genes in petunia: Sense and antisense make sense, $p$. 191-202. In A.B. Bennett and S.D. O'Neill (eds.). Plant biology. vol. 11. Wiley-Liss, New York.

Plegt, L. and R.J. Bino. 1989. $\beta$ - glucuronidase activity during development of male gametophyte from transgenic and non-transgenic plants. Mol. Gen. Genet. 216:321-327.

Shih, C.Y., E.B. Dumbroff, and J.E. Thompson. 1989. Identification of a naturally occurring inhibitor of the conversion of 1-aminocyclopropane-1-carboxylic acid to ethylene by carnation microsomes. Plant Physiol. 89:1053-1059, 